\title{
Community-based occupational therapy with a head-injured adult.
}

\author{
Elizabeth DePoy \\ Thomas Jefferson University
}

Follow this and additional works at: https://jdc.jefferson.edu/otfp

Part of the Occupational Therapy Commons

Let us know how access to this document benefits you

\section{Recommended Citation}

DePoy, Elizabeth, "Community-based occupational therapy with a head-injured adult." (1987).

Department of Occupational Therapy Faculty Papers. Paper 52.

https://jdc.jefferson.edu/otfp/52

This Article is brought to you for free and open access by the Jefferson Digital Commons. The Jefferson Digital Commons is a service of Thomas Jefferson University's Center for Teaching and Learning (CTL). The Commons is a showcase for Jefferson books and journals, peer-reviewed scholarly publications, unique historical collections from the University archives, and teaching tools. The Jefferson Digital Commons allows researchers and interested readers anywhere in the world to learn about and keep up to date with Jefferson scholarship. This article has been accepted for inclusion in Department of Occupational Therapy Faculty Papers by an authorized administrator of the Jefferson Digital Commons. For more information, please contact: JeffersonDigitalCommons@jefferson.edu. 


\section{Community-Based Occupational Therapy With a Head-Injured Adult}

\author{
Elizabeth DePoy
}

\author{
Key Words: head injuries $\bullet$ services, \\ occupational therapy $\bullet$ work
}

Elizabeth DePoy, MSW, OTR/L, is Assistant Professor, Department of Occupational Therapy, College of Allied Health Sciences, Thomas Jefferson University, Philadel. phia, Pennsylvania 19107

Editor's Note. To continue the Case Report department, we need and welcome reports that document the practice of occupational therapy for specific clinical situations. (Submit tbree copies of your manuscript to the Editor.) Guidelines are available from the Editor.
I n the early 1970 s, the National Head Injury Foundation identified 422,000 adults with permanent brain damage caused by traumatic head injury. It is estimated that 400,000 new cases of varying severity are treated in hospitals each year, the majority of whom are previously employed young adult men. Although many persons with traumatic brain injuries are able to return to productivity, approximately $35 \%$ of the adults who have been rated as mildly head injured on the Glascow Coma Scale (Teasdale \& Jennet, 1974) never return to work and have difficulty reentering society after restorative efforts are discontinued (Rosenthal, Griffith, Bond, \& Miller, 1983). These persons often remain socially isolated and nonproductive and thus are likely to develop secondary occupational dysfunction. Adults with mild head injuries often report feeling incompetent, frustrated and struggle with a loss of control over their lives (Deutch and Sawyer, 1985). If they live at home, they frequently experience increased tension in the family; this tension can lead to the dissolution of the family unit and to the unnecessary institutionalization of the brain-damaged adult. The need for community-based intervention with a focus on culturally relevant occupational function is evident. This case report describes the progress of a mildly head-injured man who worked with an occupational therapist in a homebased program to improve occupational function.

\section{Client Data}

J.M. is a 30 -year-old white man who was injured in an automobile accident when he was 24 years old. After he emerged from a 3-week coma, J.M. was admitted to an inpatient rehabilitation center. Records indicate that he was nonambulatory because of right hemiplegia, that he was severely dysarthric and therefore unintelligible, and that he demonstrated agitated behavior. Because of his inability to verbally communicate or to attend to a task for any length of time, cognition and perception were initially difficult to evaluate. Intensive speech, occupational, and physical therapy and psychological counseling were prescribed for a period of 3 months during which time J.M. made significant progress. By the time he was discharged from inpatient care J.M. was ambulatory with a walker, independent in self-care, minimally verbally communicative, and less agitated. J.M. continued outpatient counseling, occupational, speech, and physical therapy for approximately 18 months. When restorative efforts had been terminated, approximately 2 years after the accident, J.M. was reported to have exhibited mild ataxia of the right upper and lower extremities, severe dysarthria, poor social judgment, difficulty with temporal adaptation, explosive behavior, and compromised problem-solving abilities. The exact 
degree of cognitive and perceptual impairment was not clearly documented in the records.

Before his automobile accident, J.M. worked as a delivery man for a pizza shop. He was married and had two young children. J.M. reported that he enjoyed work, fishing, and drinking beer with his friends after work hours. He also reported enjoying family activities such as going to the park. Approximately 3 years after the accident, J.M.'s wife and children left him because of marital discord. J.M. remained alone in the house where he presently lives, reportedly nonproductive and isolated from all social contacts except his mother.

\section{Evaluation}

The client was referred to a private rehabilitation company by his no-fault automobile insurance carrier 6 years after his accident. The purpose of the referral was to evaluate J.M. for work potential. Because of the referral source, reimbursement for evaluation and recommended intervention was limited only by insurance carrier approval.

Initially J.M. was seen in his home by the occupational therapist during six 1 -hour sessions. During these sessions he was interviewed and observed extensively to determine his occupational functional status, occupational functional potential, goals, and interests. For most of the evaluation, unstructured interviews and observation of the client's task behavior were used as the essential assessment tools. These tools were selected according to the following criteria: (a) the absence of time constraints allowing the occupational therapist to observe the client interacting with his natural environment, (b) the client's resistance to any formalized evaluation, particularly if he was being timed, (c) the occupational therapist's judgment that for this client, the most accurate data regarding function would be obtained through unstructured evaluation. At the request of the occupational therapist, the client, although hesitantly, agreed to undergo neuropsychological testing.

Evaluation results of J.M.'s performance skills indicated that he still exhibited mild ataxia in his dominant right upper extremity and minimal ataxia in his right lower extremity. As a result, fine motor coordination was mildly impaired. Gross motor skills were minimally impaired; however, the client was able to ambulate and drive without assistive devices or automobile modifications. Although J.M. was physically capable of independence in self-care skills, he neglected his hygiene because of poor judgment, poor temporal adaptation, and poor temporal organization. J.M. still experienced severe dysarthria, but he compensated well and was able to verbally communicate without much difficulty both in person and on the telephone. Neuropsychological evaluation results confirmed the following occupational therapy findings and conclusions:

1 J.M. was able to perform concrete operations but unable to use formal operations in problem solving (A full scale IQ of 86 was reported).

2. His concentration and his attention span were within normal limits.

3. His ability to learn was moderately impaired.

4. His social judgment was poor.

5. He had mild adynamia.

6. His vision and visual perception were within normal limits.

7 He demonstrated a nonclinical depression.

8. He had the capacity for independent living and competitive employment.

J.M. fulfilled few satisfying adult roles. He owned an automobile, but he used it only to drive to his mother's house. J.M. spent most of his time in his home, where he lived alone, watching television and reading romance novels provided by his mother. Infrequently, J.M. would go to the grocery store to buy prepared foods, but he mostly relied on his mother to cook for him. He never cleaned the house and rarely washed his clothing. He had not seen his children or his estranged wife for 2 years and reported having no friends or social activities.

During the occupational therapy evaluation sessions, J.M. expressed the desire to return to work and to begin to socialize with women. However, although he was able to verbalize goals and interests, he was unable to enact them. This inability confirmed the presence of initiation problems. The client had many intact skills, but he was unable to organize them into functional routines and to initiate action to resume normative and satisfying adulthood roles.

\section{Intervention}

With the assistance of the neuropsychologist and J.M.'s active participation, the following long-term treatment goals were established:

- Help client establish independent functional daily self-care routine

- Help client acquire adult social roles by structuring daily social activity outside his home

- Assist client in securing and maintaining employment

Progress would be evaluated not by the client's acquisition of new skills, but rather by his organization of existing skills into adult roles and routines and by his independent initiation of action that would allow him to carry out these roles. 
Occupational therapy intervention took place over 2 years. The client was seen in his home, initially twice a week. Over the 2 years, intervention was gradually decreased until J.M. was able to maintain his independence through community support. Throughout the intervention, the occupational therapist used a systems approach to facilitate the client's reintegration into his environment (Kielhofner, 1983), that is, the client's individual skills, roles, and routines were addressed in the context of his home, social and, ultimately, work environments

The first phase of intervention focused on the client's daily routine. Two techniques were used: the establishment and rewarded repetition of a functional routine and environmental adaptation. A balanced schedule of daily activities, with built-in rewards for accomplishment (chosen by J.M.) was established by the therapist after J.M. verbalized his interests and values and the therapist clearly delineated them in a daily diary. Because of upper extremity impairment, J.M. was unable to write legibly, but he agreed to place a check mark next to each listed activity that he completed. For each day that he was able to successfully complete his routine, he acquired a token. After he had collected the first ten tokens, the therapist took J.M. out to lunch as previously agreed upon. Additional tokens could be used to buy services from the therapist, such as help with clothes shopping and home decorating. The initial schedule included a hygiene and grooming routine, one cooking activity a day, one housekeeping activity such as dusting or vacuuming a day, and one leisure activity inside the home a day. (Examples of leisure activities are reading, collecting pictures of home furnishings for home decorating ideas, and collecting easy recipes.) The same time schedule was followed daily until it be. came a functional routine. To facilitate J.M.'s successful integration of the daily schedule, J.M. and the therapist worked together to modify and reorganize J.M.'s home environment. For example, rooms were cleared of clutter, and objects were organized by categories and placed where the client could easily reach them. A cordless telephone was purchased for convenience and to encourage J.M. to communicate with persons outside the home.

As soon as J.M. was able to demonstrate compe. tence in a daily routine of self-care and leisure in his home, the activities were expanded to encourage his involvement in occupation outside the home. The same techniques of rewarded repetition and environmental adaptation were used. The client added occupations such as grocery shopping and banking (initially in the company of the therapist) to his activity repertoire. He was very successful at these activities because his budgeting and money handling skills were intact and of significant value to him. He was soon ready to begin an exercise program at the local YMCA. With clearance from his neurologist, the client enrolled in a group swim program for people with disabilities. The therapist met with the YMCA director to structure the swim program and to ensure that the client was able to navigate the environment independently. The swim program provided J.M. with physical activity to maintain functional skills as well as with opportunity for socialization. To help J.M. develop appropriate social skills, the therapist observed his social interactions. The following inappropriate behaviors were identified: extreme verbal aggressiveness with women, frequent interruptions, attention seeking from women. These behaviors were remediated through supplementary repetitive role playing in the client's home.

As I.M. progressed in his routine of self-care and exercise, it became possible to consider employment. J.M. had developed a daily temporal routine which closely approximated a full workday. Although problem solving was not an explicit goal, the client's problem solving abilities were consistently engaged in planning and implementing each functional objective.

To shift the focus of intervention to the workplace, a vocational counselor joined the intervention team approximately 1 year after the therapist had started to work with J.M. The vocational counselor assisted J.M. in securing interviews for realistic jobs while the occupational therapist worked with him on his interview skills. It took 6 months until the client was hired as a messenger for a print shop. Before J.M. began his employment, the occupational therapist met with the employer to obtain a job description, analyzed the job, and rehearsed the difficult tasks with the client. For example, accompanied by the therapist, J.M. familiarized himself with the geographical location which was serviced by his employer and learned the most efficient routes for travel. During J.M.'s adjustment period, the employer worked closely with the therapist to develop the skills he needed to effectively supervise J.M. J.M.'s office work space was also modified so that he could accomplish all of the components of the job. For example, the time sheet, which required handwritten recording, was redesigned for a typewriter so that the client could independently record his daily activities.

Toward the end of the intervention period, the occupational therapist referred J.M. to the local head injury support group and attended two meetings with him. J.M.'s occupational therapy was terminated when the three long-term goals were met, approximately 2 years after the initial evaluation. Over the 2 years, the client learned to organize his existing skills into satisfying and balanced adult roles. No follow-up was permitted by the insurance carrier, since it was deter- 
mined that the functions originally outlined for the occupational therapy intervention were successfully accomplished.

\section{Discussion}

Although there are many new avenues for the treatment of head-injured adults (subacute care, transitional living centers, and day care arrangements), this client clearly was a candidate for independent community living. This determination was based on the following factors.

The client had

intact capacities in cognition, self-care, and mo. bility assessed potential for competitive employment adequate financial resources

a high degree of motivation and cooperation previously exhibited ability to live independently without outside supervision

Persons who do not possess the above attributes should be considered for a more intense level of care, which would be selected on the basis of intactness of potential performance skill, the need for supervision, the potential for self-care and work, capacity for new learning, demonstrated judgment in social situations, and the ability to initiate goal-directed action.

Current health care trends, which favor a continuum of noninstitutional interventions such as those described in this report, support the need for occupational therapists to expand their practice to arenas outside the traditional rehabilitation clinic setting. Because occupational therapists are trained or educated to holistically address function in self-care, work, and leisure, they are valuable professionals in community-based treatment of the head-injured adult. Occupational therapy is the profession that focuses on occupational performance and environmental adapta. tion within an environmental context. Through organizing a client's existing skills into functional roles and routines that meet the demands of the environ. ment, and by adapting the environment to facilitate the client's occupational function, occupational therapists can work creatively with the growing population of head-injured adults to enhance their productivity, contribution to adult society, and quality of life.

\section{References}

Deutch, P. M., \& Sawyer, H. W. (1985). A guide to rebabilitation. New York: Matthew Bender.

Kielhofner, G. (Ed.). (1983). Health through occupation: Theory and practice in occupational therapy. Philadelphia: Davis.

Rosenthal, M., Griffith, M. D., Bond, M. R., \& Miller, J. D. (1983). Rebabilitation of the bead injured adult. Phila. delphia: Davis.

Teasdale, G., \& Jennet, B. (1974). Assessment of coma-impaired consciousness: A practical scale. Lancet, 2, 81-84 